\title{
BIOÉTICA - UM ENSAIO SOBRE SUA INSERÇÃO NOS CURSOS DE GRADUAÇÃO EM ENFERMAGEM ${ }^{1}$ \\ BIOETHICS -AN APPROACH ABOUT YOUR INSERT IN COURSES OF GRADUATION IN NURSING BIOÉTICA - UN ENSAYO SOBRE SU INSERCIÓN EN LOS CURSOS DE GRADUACIÓN EN ENFERMERÍA
}

\section{Joice Maria Zanatta ${ }^{2}$, Magali Roseira Boemer ${ }^{3}$}

RESUMO: O presente ensaio, referente à inserção da Bioética nos cursos de Graduação em Enfermagem, inicia-se com considerações sobre a origem da Bioética no âmbito internacional e nacional. As autoras discorrem, com base na literatura, sobre a forma que a Bioética é apresentada aos profissionais de saúde. Recorrendo a um levantamento das publicações realizadas por enfermeiros, encontram poucas publicações sobre o tema, o que as motivou para esse ensaio. As autoras alertam para a necessidade de que nos debrucemos sobre esta questão, realizando estudos com vistas a identificar qual o preparo que graduandos de Enfermagem estão tendo em seus cursos para lidar, na prática, com dilemas bioéticos.

PALAVRAS CHAVE: Bioética ; Ética; Ensino; Enfermagem.

ABSTRACT: This essay deals with the insertion of Bioethics in undergraduate Nursing courses. First, we present some considerations about the origin of Bioethics in Brazil and abroad. Next, we discuss how Bioethics is presented to health professionals, according to literature. A survey of nursing publications found few studies, a fact that motivated us to write this essay. There is a need to look into this matter, realizing studies to identify how undergraduate Nursing courses are preparing their students to deal with bioethical dilemmas in practice.

KEY WORDS: Bioethics; Ethics; Education, Nursing.

RESUMEN: El presente ensayo, referente a la inserción de la Bioética en los cursos de Graduación en Enfermería, se inicia con consideraciones sobre el origen de la Bioética en el ámbito internacional y nacional. Las autoras discuten, con base en la literatura, sobre la forma que la Bioética es presentada a los profesionales de salud. Recurriendo a una revisión de las publicaciones realizadas por enfermeros, se encuentran pocas publicaciones sobre el tema, lo que las motivó para realizar este ensayo. Las autoras alertan hacia la necesidad de que nos avoquemos sobre esta cuestión, realizando estudios con miras a identificar quien o quien preparan en esta cuestión, y que universitarios de Enfermería están teniendo esta formación en sus cursos para lidiar, en la práctica, con dilemas bioéticos.

PALABRAS CLAVE: Bioética; Ética; Ensañansa; Enfermería.
${ }^{1}$ Trabalho desenvolvido durante o Programa de Iniciação Científica - PIBIC, 2005, sob orientação da segunda autora.

Aluna do $3^{\circ}$ ano do Curso de Graduação da Escola de Enfermagem de Ribeirão Preto da Universidade de São Paulo (EERP/USP), 2005. Rua Benjamin Constant, 49, Centro Jardinópolis/SP, CEP 14680-000, joicezanatta@yahoo.com.br.

${ }^{3}$ Professora Livre-docente aposentada da Escola de Enfermagem de Ribeirão Preto da Universidade de São Paulo (EERP/USP). Coordenadora de projeto de pesquisa - CNPq. Rua Bernardino de Campos no30 ap 1001 Centro - Ribeirão Preto, SP, CEP: 14015 130, boemer@eerp.usp.br. 


\section{A INSERÇÃO DA BIOÉTICA NOS CURSOS DE GRADUAÇÃO EM ENFERMAGEM}

A proposta deste estudo foi realizar um ensaio com vistas à uma aproximação ao tema da Bioética. As autoras justificam o estudo, explicitando sua preocupação quanto ao preparo dos graduandos em enfermagem no seu lidar cotidiano com os dilemas bioéticos. Propõem a articulação dos conteúdos teóricos com as situações vivenciais dos estágios e com as demais disciplinas ministradas.

Para tanto foi realizada uma extensa revisão da literatura incluindo livros, artigos, dissertações e teses que abordam o tema da Bioética. Foi possível resgatar a gênese da Bioética no Programa Internacional e Nacional. Algumas publicações de enfermeiros foram encontradas.

Nos primórdios da cultura ocidental, a Ética foi a primeira preocupação que motivou a reflexão sobre as relações da humanidade. Desde os períodos mais arcaicos da civilização grega, as manifestações dessa reflexão inseriam-se na preocupação com a busca de significado da vida humana. Neste contexto, a Ética consiste no discernimento para encontrar, entre todos os interesses do indivíduo, do grupo, da nação e da humanidade, o critério de justa escolha. Ela não pode ser separada da experiência efetiva dos valores (SILVA, 1993).

Já a Bioética, ou ética aplicada à vida, surgiu nos Estados Unidos. Esta palavra foi, primeiramente, forjada por Van Rensselaer Potter, em 1971, mas o termo foi introduzido por André Hellegers. Potter imprimiu a ela um sentido ecológico: "ciência da sobrevivência". Já Hellegers restringe-a como ética das ciências da vida, particularmente considerada em nível do humano. Foi no plano de aplicação das biotecnologias ao homem, no domínio das ciências médicas que a bioética floresceu, em um ambiente marcado por grandes evoluções e sentimentos contraditórios. Ela emerge como novo domínio da reflexão e da prática, que toma como seu objeto específico as questões humanas na sua dimensão ética, tal como se formula no âmbito da prática clínica ou da investigação científica, e como método próprio a aplicação de sistemas éticos já estabelecidos ou de teorias a estruturar (NEVES, 1996).

A Bioética, inicialmente conceituada por Potter para referir-se à importância das ciências biológicas na melhoria da qualidade de vida, hoje é considerada como "o estudo sistemático da conduta humana na área das ciências da vida e aos cuidados da saúde, na medida em que esta conduta é encaminhada à luz de valores e princípios morais" (CLOTET, 1993).

A bioética, na atualidade, ocupa-se, principalmente, dos problemas éticos referentes ao início e fim da vida humana, dos novos métodos de fecundação, da seleção de sexo, da engenharia genética, da maternidade substitutiva, das pesquisas em seres humanos, do transplante de órgãos, dos pacientes terminais, das formas de eutanásia, entre outros temas. Os princípios da bioética, segundo
CLOTET, (1993) são: princípio da autonomia (é a autodeterminação real e universal do homem, independência da vontade, escolha individual); princípio da beneficência (ação voltada para o benefício do ser humano) e o princípio da justiça (tratar os iguais como iguais e os diferentes como diferentes na justa medida da sua desigualdade, reconhecer igualmente, sem distinção, o direito de cada um).

O termo Bioética é definido pela International Association of Bioethics, como: "estudos dos aspectos éticos, sociais, legais, filosóficos e outros aspectos afins inerentes à assistência médica e às ciências biológicas" (CAMPBELL, 2000).

Em 1995, a Bioética é definida, pela segunda Edição da Ecyclopedia of Bioethics, como sendo o "estudo sistemático das dimensões morais - incluindo visão, decisão e normas morais - das ciências da vida e do cuidado da saúde, utilizando uma variedade de metodologias éticas num contexto multidisciplinar" (BARCHIFONTAINE \& PESSINI, 1994). Surge no panorama científico das novas descobertas como o estudo interdisciplinar dos problemas criados pelo avanço biomédico, pela nova direção dada na sociedade e seu sistema de valores, prevalecendo a imprescindível proteção da vida humana diante de todas as inovações técnico-científicas na área das ciências da vida.

De acordo com LENOIR (1996), a Bioética visa alertar as sociedades a respeito das conseqüências do avanço técnico-científico incontrolado e promover uma forma de controle democrático do processo de inovação técnico-científico. Essa autora lembra que o ensino da bioética aos profissionais de saúde deve ser provido de um caráter preciso e não limitar-se à reflexão geral de princípios; deve ser concebido como resultado da cultura geral do século XXI, permitindo a todos exercer suas responsabilidades próprias diante das novas situações provenientes do avanço das ciências da vida.

Segundo GOMES (1996), a formação ética do profissional de saúde deve ser iniciada nas disciplinas básicas do estágio pré-clínico com noções gerais de ética, um curso teórico e substantivo de introdução à Bioética, a ética aplicada ao ambiente do ensino e relativa ao respeito ao cadáver, aos mestres, animais de experiência e até à postura acadêmica. A razão da implantação da ética profissional de saúde está ligada à necessidade de formar uma consciência ética de relação ou imprimir, na personalidade do educando, um forte acento de respeito incondicional aos direitos fundamentais e também oferecer ao profissional de saúde a postura ética aprendida e estimulada, saudável e proveitosa na relação com o paciente, outros profissionais e a sociedade em geral.

Os profissionais da área de saúde devem conciliar, no seu exercício profissional, além da ciência e tecnologia, um sólido embasamento ético-moral. Um profissional competente é aquele que reúne qualificação científica, tecnológica e ética, ciente de que, frente a um dilema difícil, deve solicitar auxílio ao Comitê de Ética (FRANCISCONI et al, 2002). 
No Brasil, apesar de a Bioética ter sido, de certa forma, "tardia" por ter florescido apenas nos anos noventa, ela cresceu significativamente conquistando admiração e respeitabilidade internacional. Diversas universidades brasileiras já iniciaram programas de pós-graduação lato sensu em bioética; além disso, os currículos de formação de futuros profissionais de campo relacionados às ciências da vida e da saúde estão procurando ir além da deontologia (ramo da ética que trata dos deveres), da medicina legal e da ética profissional, passando a contemplar, nas grades curriculares, conteúdos relacionados à bioética (GARRAFA e PESSINI, 2003).

O estudo de novas temáticas e discussões com o surgimento da Ética Prática ou Bioética propicia ao aluno o desenvolvimento da visão crítica sobre a pluralidade de valores que permeiam as relações em Saúde. As Diretrizes Curriculares Nacionais dos Cursos de Graduação em Enfermagem (CNE/ME/BR) reforçam essa perspectiva ao enfatizar a importância de conhecimentos em ética e bioética para a formação generalista do futuro profissional de Enfermagem (RIBEIRO, 2004).

Voltando o olhar especificamente para a Escola de Enfermagem de Ribeirão Preto da Universidade de São Paulo (EERP / USP), temos que ela foi fundada, em 1953, por Glete de Alcântara - primeira professora de Enfermagem da América Latina com o título de Professor Catedrático de História da Enfermagem e Ética (1963). A Escola teve seu primeiro programa curricular aprovado pela Lei 5.970/1960, quando ainda anexa à Faculdade de Medicina de Ribeirão Preto (FMRP / USP). Este programa abordava a Ética Geral e a Ética Profissional. $O$ primeiro dizia respeito à "moral teórica" como reflexão filosófica acerca das ações humanas, bem como noções conceituais fundamentais como "os valores, o bem, o direito, o dever, a obrigação e a responsabilidade" (ALCÂNTARA, 1966). O segundo centrava-se no estudo das normas que regiam o exercício da Enfermagem, baseado no "Código de Ética da Associação Brasileira de Enfermagem". Para doutora Glete, a concepção sobre o ensino e o papel da Ética para o curso de Enfermagem ultrapassava o ensino teórico: "Ele está integrado em todas as disciplinas do currículo, mormente nas de enfermagem, porque o estudante aprende Ética, sobretudo, com a vivência dos problemas que ocorrem diariamente e com o exemplo daqueles a quem está relacionado em todas as situações de aprendizagem" (ALCÂNTARA, 1966). Tal visão, do papel fundamental da Ética, perpassou todos os conteúdos disciplinares posteriores, elaborados na história dessa Escola.

Segundo Ribeiro (2004), o quadro atual da área de Ética no ensino de Graduação em Enfermagem na EERP/USP originou-se de uma reformulação das disciplinas, realizada a partir de 1998, que optou pelo desmembramento de História da Enfermagem, Ética Fundamental e Legislação, que se tornaram conteúdos ministrados separadamente, sob os títulos de História da Enfermagem, Fundamentos de Ética, Legislação em Enfermagem. Naquele mesmo ano, foi criada a disciplina de Bioética e foi extinta Antropologia Filosófica, incorporando-se muitos tópicos dessa disciplina em Fundamentos de Ética. Tal reformulação resultou em uma nova perspectiva para a formação ética do aluno, que passou a dispor de disciplinas voltadas para a ética filosófica, a ética normativa e a ética prática, ministradas nessa ordem, para que o aluno desenvolvesse um grau de compreensão e de maturidade necessárias para cada discussão durante o curso de graduação.

SIMINO \& BOEMER (2004) realizaram um estudo onde verificaram que a enfermagem possui periódicos de grande contribuição para o estímulo e divulgação de sua produção científica; no entanto, não existe um periódico que aborde, especificamente, temas bioéticos. Os artigos analisados nesse estudo totalizaram 27. Destes, 48,15\% (13 artigos) enfocavam: o código de ética dos enfermeiros e a tomada de decisões éticas, o cuidado ao idoso segundo a perspectiva do profissional enfermeiro, a anotação de enfermagem, a comunicação entre os profissionais e o paciente, a autonomia do paciente $\mathrm{e}$ do enfermeiro e a relação entre os enfermeiros e outros profissionais. Sete artigos $(26,92 \%)$ abordavam a organização da assistência ao paciente no que tange a regimentos que controlam pesquisas com seres humanos e sua importância, a tecnologia versus humanização no modelo assistencial vigente, o papel do enfermeiro frente a esses dilemas e princípios da autonomia e beneficência na humanização da assistência e dependência dos pacientes. Dois artigos $(7,41 \%)$ tratavam da estagnação da Bioética no modelo principialista, surgimento da corrente feminista e a Bioética refletida nas tecnologias reprodutivas. Outro dado encontrado foi que $75,51 \%$ dos autores desses artigos são enfermeiros docentes (doutores/doutorandos).

O levantamento e a revisão dos artigos realizados pelas autoras expressam o quanto é oportuna a afirmação de LENOIR (1996), ao dizer que o ensino da bioética aos profissionais de saúde deve ser provido de um caráter preciso e não limitar-se à reflexão geral de princípios. Considerando que a Bioética trata de questões altamente relevantes para os profissionais de Enfermagem, sendo a apropriação de seus conteúdos primordial em sua formação, ela não pode, de fato, restringir-se a princípios gerais.

Refletindo a respeito da formação no Curso de graduação em Enfermagem observamos que há hesitação, por parte dos graduandos, em lidar com situações que envolvam questões de natureza bioética por sentirem-se despreparados. Consideramos que o investimento acadêmico tem sido ainda muito pequeno e incipiente, sem grandes possibilidades para reflexão. Cremos que uma carga horária de 30 horas destinada à disciplina de Bioética seja pequena, para formar, nos alunos, uma consciência ética para lidar com os muitos dilemas bioéticos.

Algumas questões inerentes à profissão nos inquietam muito: Será que os graduandos de 
Enfermagem que estão cursando suas faculdades estão sendo bem preparados para lidar, na prática, com dilemas bioéticos? Será que estão desenvolvendo uma consciência a respeito do assunto ou, como disse Lenoir, estão refletindo apenas sobre princípios? Como a Bioética está se mostrando aos graduandos?

Participando do III Congresso Brasileiro de Nanatologia e Bioética, realizado em São Paulo/SP, em abril de 2005, foi possível ter uma visão mais ampla de como a Bioética está presente em nosso meio, de como ela se apresenta em nosso cotidiano. Esses dilemas se nos apresentam a toda hora, no exercício de nossa profissão.

Assim sendo, vemos a necessidade de nos debruçarmos sobre esta questão, realizando estudos com vistas a identificar qual o preparo que os graduandos de Enfermagem estão tendo em seus cursos para lidar, na prática, com dilemas bioéticos.

Tais estudos deverão voltar-se inclusive para a averiguação de uma integração da Bioética com as demais disciplinas curriculares, conforme já recomendava ALCÂNTARA (1966). Acreditamos que estudos dessa natureza possam ser realizados nas diferentes regiões do país, por diferentes pesquisadores de forma a podermos ter um diagnóstico da inserção da Bioética nos cursos de Graduação em Enfermagem.

Nesse sentido, o ensaio permitiu explicitar alguns questionamentos e propor novos estudos que possam identificar e analisar a inserção da Bioética nos cursos de graduação em Enfermagem. Muito embora um ensaio não se proponha a conclusões, o estudo possibilitou às autoras a gênese de questionamentos, reflexões e ponderações sobre a inserção da Bioética nos cursos de graduação em Enfermagem, abrindo possibilidades de investigações.

\section{REFERÊNCIAS BIBLIOGRÁFICAS:}

ALCÂNTARA, G. In: RIBEIRO, C. R. O. A contribuição da área de Filosofia, Ética e Bioética na Escola de Enfermagem de Ribeirão Preto- USP, 1966. on-line. Brazilian Journal of Nursing (objn-issn 1676-4285) [online], dezembro 2004.

BARCHIFONTAINE, C. P.; PESSINI, L. Problemas atuais de bioética. $2^{\circ}$ ed. Brasil: Loyola, p. 367, 1994.

CAMPBELL, A. In: A Bioética no século XXI. Coleção saúde, cidadania e bioética, editora Universidade de Brasília, Brasília, 2000.

CLOTET, J. Por que bioética? Revista Bioética, v.1, n.1, p. 14-9, 1993.

FRANCISCONI, C. F., GOLDIM, J. R., LOPES, M. H. I. O papel dos Comitês de Bioética na humanização da assistência à saúde. Revista Bioética, v. 10, n. 2, p. 147-157, 2002.

GARRAFA, V.; PESSINI, L. Bioética: Poder e Injustiça. Editora Loyola, Brasília, p. 522, 2003.

GOMES, J. C. M. O atual Ensino da ética para os profissionais de saúde e seus Reflexos no Cotidiano do Povo Brasileiro. Revista Bioética, v. 4, n. 1, p. 5364, 1996.

LENOIR, N. Promover o Ensino de Bioética no Mundo. Revista Bioética, v. 4, n. 1, p. 65-70, 1996.

NEVES, M. C. P. A fundamentação antropológica da Bioética. Revista Bioética, v. 4, n. 1, p. 07-16, 1996.

RIBEIRO, C. R. O, A contribuição da área de Filosofia, Ética e Bioética na Escola de Enfermagem de Ribeirão Preto - USP, on-line Brazilian Journal of Nursing (objnissn 1676-4285) [on-line], dezembro 2004.

SILVA, F. L. Breve Panorama Histórico da Ética. Revista Bioética, Título: Bioética, v. 1, nº. 1, p. 7 -11, 1993.

SIMINO, G. P. R.; BOEMER, M. R. Enfoque Bioético na produção científica dos enfermeiros caracterização e análise. Revista Brasileira de Enfermagem, v. 57, n. 1, p. 40-3, 2004.

Texto recebido em 01/12/2005.

Publicação aprovada em 31/12/2005 